\title{
Prospective study of quantitative aspects of audit in a large general histopathology laboratory
}

\author{
J St J Thomas, A M Lessells, M A McIntyre, H S Klys, J N Webb
}

\begin{abstract}
A non-computerised method of accurate prospective analysis of the quantitative aspects of the work of a general histopathology laboratory was devised. The method entails monitoring the progress of all biopsy and cytology specimens through the laboratory during selected monthly periods of study. The data collected include details of specimen type, block/section/stain details for each specimen, and information about the timed progress through technical, medical, and secretarial stages of specimen/report handling.

The results give a detailed breakdown of the biopsy and cytology workload of this department. They give information about the rate of passage of specimens through the system and identify reasons for delay in the reporting of some cases. The method is easy to operate and will allow for the analysis of specific effectsfor example, stafi changes-on the efficiency of the department. The data will also provide some of the information required for the costing of histopathology laboratory services, and the type of information obtained will probably become a necessary requirement for laboratory accreditation.
\end{abstract}

The introduction of modern management techniques to the NHS has stimulated the need for effective audit of clinical and diagnostic work practices from the qualitative and quantitative points of view, both internally and externally, with the objective of improving standards and efficiency. Indeed, the implementation of an effective and comprehensive audit system will be mandatory in laboratory management ${ }^{1}$ and is likely to become a requirement for accreditation of a laboratory by the Royal College of Pathologists.

A non-computerised method for the examination of the quantitative aspects of the biopsy

Accepted for publication 12 June 1991 and cytology workload of a general pathology laboratory was devised with specific emphasis being placed on turnaround times to identify areas where improvements might be made.

\section{Methods}

The Pathology Department in the Western General Hospital serves the population of the north of Edinburgh and some outlying districts. The annual workload is as follows: 10000 surgical specimens; 400 hospital necropsies; and 6000 non-gynaecological cytology specimens. The department is staffed by four whole time NHS consultants. There is one trainee pathologist. A prospective analysis of our biopsy handling was conducted over three separate monthly periods and similar aspects of our cytology handling were examined over two months. Each member of medical staff was given standardised forms for biopsy and cytology specimens which were filled out on a case by case basis. The forms were filled in by the pathologist while reporting cases. The headings under which biopsy data were entered are listed in table 1 . They cover the major events that occur during the transit of a specimen through the laboratory. These headings were arranged across the top of a single A4 sheet which would then accommodate the data from about 25 cases.

THE BIOPSY SPECIMEN REPORT FORM

1 Specimen details

Specimens were categorised as A, B, or C according to the amount of effort required by the pathologist to prepare the specimen before processing. Specimens that were not handled by the pathologist but placed directly into cassettes by the technician-for example, endoscopic biopsy specimens, prostatic chippings, endometrial curettings-were categorised as $\mathbf{A}$. Specimens that were routinely examined and described by the pathologist but required a relatively small amount of time for this and which tended to result in a small number of blocks (usually three or less) such as skin biopsy specimens, gall bladders, and appendices were categorised as B. Larger specimens which required a considerable amount of preparation time and often generated a large number of blocks were categorised as C. The number of special stains or immunohistochemical stains was recorded. Other analyses such as plastic histology or cytogenetic analysis were recorded. 
Table 2 Cytology reporting form headings

\begin{tabular}{lll}
\hline Specimen details & Turnround times & Other information \\
\hline Case No & Specimen received & Further discussion \\
Specimen type & Slides received & Other comments \\
Slides (No) & Case reported & Report telephoned \\
Extra slides (No) & Report typed & \\
Special stains (No) & & \\
Immunological stains (No) & & \\
\hline
\end{tabular}

\section{Turnround times}

In the "specimen recieved" column the pathologist recorded the number of days that had elapsed between the dating of the request form by the referring clinician and the receipt of the specimen by the department. If the specimen was received on the same day the column was scored 0 , if the specimen was received the next day the column was scored 1 , etc. In the "slides received" column the pathologist recorded the time in days from receipt of the specimen to receipt of slides for reporting. In this department the standard delay is less than 24 hoursthat is, specimens that are received on one day are processed overnight and the slides are available from about $10.30 \mathrm{am}$ on the following day. This standard situation was recorded as 0 . If the trimming of the specimen was delayed for any reason-for example, due to overnight fixation-then the delay in days was recorded. It is the practice of this department to report cases on the day of receipt of the slides with the dictated report given to the secretarial staff by the end of that working day. The typed report is usually available for signing and despatch on the day following dictation. This standard situation was recorded in the "reported" and "typed" columns as 0 . The deviation in days from this norm was recorded. This system permitted exceptionally easy assessment of our results as the number of days' delay in any segment of the process could be identified easily and analysed.

3 Other information

The "further discussion" column allowed the

Table 3 Biopsy specimen details

\begin{tabular}{|c|c|c|c|}
\hline \multicolumn{4}{|l|}{ Category data: } \\
\hline \multicolumn{3}{|l|}{ Total No of cases } & $\begin{array}{l}\text { March } \\
725\end{array}$ \\
\hline Category (No/\%) & & & \\
\hline $\begin{array}{l}\mathbf{A} \\
\mathbf{B}\end{array}$ & $\begin{array}{l}380(56 \%) \\
240(36 \%)\end{array}$ & $\begin{array}{l}359(47 \%) \\
322(42 \%)\end{array}$ & $\begin{array}{l}411(57 \%) \\
241(33 \%)\end{array}$ \\
\hline & $60(9 \%)$ & $80(10 \%)$ & $73(10 \%)$ \\
\hline \multicolumn{4}{|l|}{$\begin{array}{l}\text { Total No of blocks } \\
\text { By category: }\end{array}$} \\
\hline & & & \\
\hline $\mathbf{B}$ & 545 & 609 & 505 \\
\hline & & & \\
\hline \multicolumn{4}{|l|}{$\begin{array}{l}\text { Blocks per case: } \\
\text { By category: }\end{array}$} \\
\hline By category: & 1.5 & 1.3 & 1.6 \\
\hline$\stackrel{B}{\mathbf{C}}$ & $2 \cdot 3$ & 1.9 & $2 \cdot 1$ \\
\hline \multirow{2}{*}{\multicolumn{4}{|c|}{ Additional investigations: }} \\
\hline & & & \\
\hline & $69(10 \%)$ & $69(9 \%)$ & $44(6 \%)$ \\
\hline $\begin{array}{l}\text { No of stains } \\
\text { Stains per case }\end{array}$ & 174 & 210 & 105 \\
\hline \multicolumn{4}{|l|}{$\begin{array}{l}\text { Stains per case } \\
\text { Immunohistochemistry: }\end{array}$} \\
\hline $\begin{array}{l}\text { Immunohistochemistry: } \\
\text { Cases }\end{array}$ & & $18(2.3 \%)$ & $10(1.4 \%)$ \\
\hline $\begin{array}{l}\text { Cases } \\
\text { No of stains }\end{array}$ & $51(2.0 \%)$ & 44 & $14(1.4 \%)$ \\
\hline $\begin{array}{l}\text { Stains per case } \\
\text { Other: }\end{array}$ & $2 \cdot 8$ & 2.4 & 1.4 \\
\hline \multicolumn{4}{|l|}{ Other: } \\
\hline Total cases & 22 & 44 & \\
\hline Frozen sections & 10 & 12 & 13 \\
\hline Plastic sect & 11 & 31 & 23 \\
\hline Electron microscopy & 1 & 1 & 4 \\
\hline
\end{tabular}

pathologist to identify those cases where a telephoned report had been deemed necessary or-for example, when a case had been discussed either over the telephone or at a clinicopathological conference. The "other comments" column permitted the recording of a frozen section or other detail not recorded elsewhere.

\section{THE CYTOLOGY REPORT FORM}

Minor modifications only were required to adapt the basic scheme outlined above for cytology specimens. The headings used in the cytology data report form are listed in table 2 . These headings were arranged across the top of a single A4 sheet as described for the biopsy specimens. We did not include seminal analyses in our cytology audit data. These account for about 120 cytology cases each month.

For the sake of efficiency and uniformity the same pathologist carried out the collation of all the results.

\section{Results}

The results for the three monthly periods of study of the biopsy specimens and the two months of study for cytology are summarised in tables 3-5.

The biopsy specimen details (table 3) are remarkably consistent. About $50 \%$ of specimens are processed completely before being seen by the pathologist (category $\mathrm{A}$ ) and about $10 \%$ of specimens require a major contribution by the pathologist before processing (category C). Numbers of blocks and special stains are also remarkably consistent.

The cytology specimen details (table 4) again show a consistency of monthly workload, although some variation in the relative proportions of different specimen types was noted.

The turnround times for biopsy specimens and cytology (table 5) show that $85-90 \%$ of biopsy and cytology cases are reported by the pathologist on the same day that the slides are received. The different processing methods for biopsy and cytology specimens are reflected by the fact that about $60 \%$ of cytology specimens are processed completely and are ready for reporting on the same day as receipt of the specimen.

\section{Discussion}

Approaches to audit in the pathology laboratory may be qualitative or quantitative. Methods of assessment of the quality of practice include: (i) random sample review; (ii) External Quality Assessment (EQA) schemes; and (iii) clinical case conferences. Random sample review is well established in cervical cytology screening and is now beginning to be applied in some histopathology laboratories where $1-5 \%$ of cases are reviewed retrospectively to examine all aspects of the quality of the report given. The random sample quality assessment method is a necessary tool in pathology audit because errors are made unknowingly and therefore peer review must depend 
Table 4 Cytology specimen details

\begin{tabular}{lll}
\hline & October & March \\
\hline Total No of cases & 276 & 284 \\
Total No of slides & 690 & 612 \\
Extra slides prepared (cases) & $53(29)$ & $47(21)$ \\
Special stains (cases) & $53(32)$ & $17(11)$ \\
Immunocytochemistry (cases) & $7(5)$ & $10(6)$ \\
Specimen type: & $98(35 \%)$ & $94(33 \%)$ \\
Sputum & $69(25 \%)$ & $35(13 \%)$ \\
Fine needle aspiration & $41(15 \%)$ & $99(34 \%)$ \\
Urine & $37(13 \%)$ & $37(13 \%)$ \\
Fluids & $16(6 \%)$ & $14(5 \%)$ \\
Brushings (bronchial and gastrointestinal) & $11(4 \%)$ & $4(1.5 \%)$ \\
Washings & & \\
\hline
\end{tabular}

on systematic selection of cases from the daily work load, irrespective of anybody's opinion of the relative importance of a particular type of specimen. $^{2}$ A variation to this approach is achieved by targetting the review towards a particular type of specimen-for example, gastric biopsies - allowing a detailed retrospective analysis of one particular area to be made. This approach is more comparable with that used for internal audit by some physicians. ${ }^{3}$ Voluntary External Quality Assessment (EQA) schemes ${ }^{4}$ are organised so that a selection of cases at the more difficult end of the diagnostic spectrum is circulated to participants who send their diagnoses to a local coordinator who scores responses against a standard set either by consensus or a recognised expert. EQA schemes do not test a pathologist's day to day working practice but, rather, make available diagnostic problems which will tend to broaden his/her experience-education rather than audit. ${ }^{5}$ Whether EQA schemes are a valid method of measuring a pathologist's continuing diagnostic competence is debatable. It is also questionable whether health authorities will accept such an activity as a valid form of audit even though the Royal College of Pathologists has recommended such an approach. ${ }^{6}$

An important internal audit system that runs in many pathology departments is the routine review of selected specimens in the context of regular departmental clinical meetings: problem cases relating to a particular specialty are discussed and their pathology reviewed. Detailed records of these meetings are now kept as part of the documentation of departmental audit.

A second, complementary aspect of audit is quantitative where times for specimen delivery, section preparation, reporting and secretarial output are assessed. This study of the quantitative aspects of the running of this pathology department should enable problem areas to be identified and improved. ${ }^{2}$ Much of the "specimen details" information gathered in this study is part of the normal statistical information that laboratories gather routinely and which forms the basis for their annual returns. Such information is usually collected by technical staff and is an essential part of good laboratory management. The approach that we have adopted ensured that during the study months the pathologists took responsibility for the analysis of all points along the laboratory "production line". These "spot check" audits showed to all the laboratory staff a measure of interest by the medical staff in the working of the laboratory-an aspect of audit that is germane to management. This approach also permitted the study of additional components of a pathologist's workload, such as the frequency of reviewing previous material. Some time was required to explain the reasons for our audit to our technical and secretarial staff who were initially suspicious of our motives.

With regard to the resource implications of this technique our system took a minimum amount of time to complete the forms, adding seconds to the reporting time of a single biopsy or cytology case. It is estimated that the total time spent in completing the forms by all pathologists a month is about two hours; the analysis of a monthly set of data took a further three to four hours.

These data give a case by case breakdown of our workload, including detailed information about which types of specimen seemed to be more labour intensive or costly than othersinformation that is rarely available from the global statistics produced by many laboratories in their annual returns. Nevertheless, we do not propose to abandon the gathering of "global" data by technical staff. Our system is not entirely fool-proof and very occasional cases do seem to go astray because a pathologist has forgotten to record the case on the form. This is an unusual occurrence and both the technicalled and pathologist-led data collection methods, far from reduplicating effort unnecessarily, provide a double-checking of the system. Furthermore, we felt that the quality of

Table 5 Turnround times: biopsies and cytology

\begin{tabular}{|c|c|c|c|c|c|}
\hline & \multicolumn{3}{|l|}{ Biopsies } & \multicolumn{2}{|l|}{ Cytology } \\
\hline & August & November & March & October & March \\
\hline $\begin{array}{l}\text { Specimen received: } \\
\text { Arrive same day (\%) } \\
\text { Arrive next day (\%) } \\
\text { Arrive later }(\%)\end{array}$ & $\begin{array}{r}73 \\
21 \\
6\end{array}$ & $\begin{array}{l}61 \\
25 \\
10\end{array}$ & $\begin{array}{l}57^{\star} \\
35 \\
4.5\end{array}$ & $\begin{array}{r}49 \\
43 \\
6\end{array}$ & $\begin{array}{c}55^{\star} \\
25 \\
2\end{array}$ \\
\hline $\begin{array}{l}\text { Slides received: } \\
\text { Arrive same day (\%) } \\
\text { Arrive next day (\%) } \\
\text { Arrive day after }(\%) \\
\text { Arrive later }(\%)\end{array}$ & $\begin{array}{l}\overline{95} \\
3.5 \\
1.5\end{array}$ & $\begin{array}{r}- \\
90 \\
8 \\
2\end{array}$ & $\begin{array}{r}\overline{94} \\
- \\
\end{array}$ & $\begin{array}{r}57 \\
42 \\
<1 \\
-\end{array}$ & $\begin{array}{l}60 \\
40 \\
-\end{array}$ \\
\hline $\begin{array}{l}\text { Slides reported: } \\
\text { Same day as recd (\%) } \\
\text { Next day (\%) } \\
\text { Later }(\%)\end{array}$ & $\begin{array}{r}94 \\
4 \\
2\end{array}$ & $\begin{array}{r}83 \\
8 \\
9\end{array}$ & $\begin{array}{r}86 \\
11 \\
1\end{array}$ & $\begin{array}{r}85 \\
13 \\
1\end{array}$ & $\begin{array}{l}88 \\
12 \\
-\end{array}$ \\
\hline $\begin{array}{l}\text { Reports typed: } \\
\text { Within } 24 \mathrm{~h}\end{array}$ & $95 \%$ & $95 \%$ & $95 \%$ & $100 \%$ & $95 \%$ \\
\hline
\end{tabular}

*In about $7 \%$ of biopsy and cytology requests in March the form was undated and therefore no estimate could be given for the amount of time taken for a specimen to reach the laboratory. 
the data that we collected would have been impoverished greatly by the absence of "specimen details" information for each case.

The small number of months that we have analysed seem to be representative of our annual workload, the first biopsy month (August) representing $89 \%$ of our average monthly biopsy caseload, with the second and third months (November and March) representing $99 \%$ and $94 \%$ of the average, respectively. The specimen details in the three months were remarkably similar. Likewise, our October and March cytology data represented $101 \%$ and $102 \%$ of our average monthly nonseminal cytology caseload. The turnround times presented here are well within the limits of acceptability quoted in previous studies, ${ }^{27}$ with $90 \%$ or more biopsy specimens taking less than $\mathbf{4 8}$ hours from receipt to the production of a typed report, with an even greater figure recorded for our cytology specimens. A comparison of our turnround time data with the figures quoted by a comparably sized British laboratory ${ }^{7}$ where 80 cases were analysed are very favourable indeed, and in contrast to those results we found no significant delay caused by a specimen belonging to our category $\mathrm{C}$, although we accept that our higher categories may not be directly comparable with those in other studies. Our case by case system of analysis permits easy identification of those cases which take a longer time to pass through the system and in most of these a good reason for the delay could be identified-performance of special stains, immunhistochemistry, or case referral. Furthermore, we note from our returns that almost all cases that were delayed were recorded as having a telephoned report as an interim communication to the clinician. The delayed specimens fell fairly evenly among the three category groups.

These data have provided baseline information about the running of this department. It is proposed to update this information at three to four monthly intervals. This frequency should provide a balance between the value derived from the audit and the minor inconvenience experienced gathering the data. A three to four monthly interval should also minimise any lapses of enthusiasm that inevitably occur during such audits. The amount of information obtained in this prospective study is likely to be more detailed and accurate than in a retrospective study which would probably rely on report scrutiny. This simple approach permits the objective monitoring of the efficiency of a department and a study of aspects of pathology that are outside a particular department's control such as van delivery of specimens from outside hospitals. It could also allow a detailed costing of the service to be set up. This is likely to be an integral part of departmental administration in the near future. This system could be easily applied to answer questions about the resource implications of a particular aspect of a laboratory's work-for example, the likely effects of doubling a laboratory's gynaecology workload. Our method of specimen categorisation is not rigorous and in the future it is proposed to try an internationally recognised system of specimen classification such as the WELCAN method. ${ }^{8}$ An appropriate system would, however, need to include an estimate of medical staff input to a case. This problem was addressed by our attempt to assign an output code to each case, but we found this difficult to apply consistently and will seek a more accurate system in the future.

Although our turnround times are within the range recommended by many laboratories in the $\mathrm{USA}^{2}$ and the results of British study reported recently, ${ }^{7}$ we felt that the very act of self-monitoring that we undertook during the study months acted as a stimulus to efficient throughput by all members of the department. In addition to using this scheme on a regular basis to monitor quantitative aspects of the day to day biopsy and cytology practice, a modification of this scheme could be applied to our necropsy practice. It will be essential to integrate this scheme with a quality assessment scheme in the future and it is proposed to carry out a retrospective quality assessment on a percentage of the cases examined in a particular month that had already been audited using the quantitative approach described here.

1 Audit commission. The Pathology Services: A management review. London: HMSO, 1991.

2 Cowan DF. Quality assurance in anatomic pathology Arch Pathol Lab Med 1990;114:129-34.

3 Royal College of Physicians. Medical audit: A first report. London: Royal College of Physicians, 1989.

4 Lee FD, Burnett RA. Quality assurance in histopathology. $J$ Pathol 1987;152:247-51.

5 Morson BC. Quality assurance and medical audit in histopathology. J Clin Pathol 1983;36:1202.

6 Registrar's report: Royal College of Pathologists. Bulletin of The Royal College of Pathologists 1983;42:9.

7 Zuk JA, Kenyon WE, Myskow MW; Audit in histopathology: an internal quality assessment scheme with analysis of preliminary results. J Clin Pathol 1991;44:10-16.

8 Department of Health. Welcan Workload measurement system for pathology: manual with schedule of values. 1988-89 Edition. Cardiff: DHSS. 